\title{
Growth inhibition of Candida species by Wickerhamomyces anomalus mycocin and a lactone compound of Aureobasidium pullulans
}

\author{
Sun-Tee Tay*, Su-Lin Lim and Hui-Wee Tan
}

\begin{abstract}
Background: The increasing resistance of Candida yeasts towards antifungal compounds and the limited choice of therapeutic drugs have spurred great interest amongst the scientific community to search for alternative anti-Candida compounds. Mycocins and fungal metabolites have been reported to have the potential for treatment of fungal infections. In this study, the growth inhibition of Candida species by a mycocin produced by Wickerhamomyces anomalus and a lactone compound from Aureobasidium pullulans were investigated.

Methods: Mycocin was purified from the culture supernatant of an environmental isolate of $W$. anomalus using Sephadex G-75 gel filtration column chromatography. The mycocin preparation was subjected to SDS-PAGE analysis followed by MALDI TOF/TOF mass spectrometry analysis. The thermal and temperature stability of the mycocin were determined. The glucanase activity of the mycocin was investigated by substrate staining of the mycocin with 4-methyl-umbelliferyl-B-D-glucoside (MUG). Gas chromatography mass spectrometry (GCMS) analysis was used to identify anti-Candida metabolite in the culture supernatant of an environmental isolate of Aureobasidium pullulans. The inhibitory effects of the anti-Candida compound against planktonic and biofilm cultures of various Candida species were determined using broth microdilution and biofilm quantitation methods.

Results: A mycocin active against Candida mesorugosa but not C. albicans, C. parapsilosis and C. krusei was isolated from the culture supernatant of $W$. anomalus in this study. The mycocin, identified as exo- $\beta-1,3$ glucanase by MALDI TOF/TOF mass spectrometry, was stable at $\mathrm{pH} 3-6$ and temperature ranging from $4-37^{\circ} \mathrm{C}$. The glucanase activity of the mycocin was confirmed by substrate staining with MUG. 5-hydroxy-2-decenoic acid lactone (HDCL) was identified from the culture supernatant of A. pullulans. Using a commercial source of HDCL, the planktonic and biofilm MICs of HDCL against various Candida species were determined in this study.
\end{abstract}

Conclusions: $W$. anomalus mycocin demonstrated a narrow spectrum of activity targeting only against $C$. mesorugosa, while HDCL demonstrated a broad spectrum of inhibitory action against multiple Candida species. The growth inhibition of $W$. anomalus mycocin and the lactone compound from A. pullulans against Candida yeasts should be further explored for therapeutic potentials against candidiasis.

Keywords: Aureobasidium pullulans, Candida, 5-hydroxy-2-decenoic acid lactone, Glucanase, Mycocin, Wickerhamomyces anomalus

\footnotetext{
* Correspondence: tayst@um.edu.my

Department of Medical Microbiology, Faculty of Medicine, University of

Malaya, 50603 Kuala Lumpur, Malaysia
}

\section{Biomed Central}

(c) 2014 Tay et al.; licensee BioMed Central Ltd. This is an Open Access article distributed under the terms of the Creative Commons Attribution License (http://creativecommons.org/licenses/by/2.0), which permits unrestricted use, distribution, and reproduction in any medium, provided the original work is properly credited. The Creative Commons Public Domain Dedication waiver (http://creativecommons.org/publicdomain/zero/1.0/) applies to the data made available in this article unless otherwise stated. 


\section{Background}

Mycocinogenic or "killer" yeasts secrete proteinaceous mycocins (also known as killer toxins) that are lethal to other yeast strains but to which the producing yeasts are immune [1,2]. Since the first discovery of killer toxin-secreting strains of Saccharomyces cerevisiae [3], yeast killer phenomenon has been documented in many different yeast species and genera from the environment, including Wickerhamomyces anomalus (previously known as Pichia anomala and Hansenula anomala) and Aureobasidium pullulans [4-9]. Both yeasts have been reported to have many applications in food fermentation, biocontrol and production of therapeutic molecules $[7,10]$. The antifungal activity of $W$. anomalus has been associated with glucanase-induced lysis [7], while the production of many metabolites, enzymes and antibiotics by $A$. pullulans has been important for its biocontrol activity [10].

Candida is a medically important yeast pathogen which causes mucocutaneous and life-threatening systemic infections in susceptible individuals. Recent investigation based on molecular approach suggests that the genus is not monophyletic, and the relationships among various Candida species are not clearly resolved [11]. Amongst the Candida species, Candida albicans is the most predominant cause of candidiasis; however, the incidence of infections caused by non-albicans Candida species such as C. rugosa species complex has also increased [12,13].

Candidiasis is usually associated with biofilm formation on the indwelling medical devices. Biofilms cells are embedded within an extracellular matrix and are difficult to treat as the cells are significantly more resistant to antimicrobial agents $[14,15]$. Several mycocins have been reported to have the potential for treatment against fungal infections including candidiasis [16-18]. Additionally, microbial metabolites such as ethanol, isoamyl alcohol, 2-phenylethanol, 1-dodecanol, Enerolidol, glycolipid biosurfactant and signalling molecules secreted in the yeast culture filtrates have been known to affect the growth of C. albicans biofilm [19,20]. For instance, farnesol is a quorum-sensing molecule which inhibits pseudohyphae transition and biofilm formation in C. albicans $[21,22]$.

Due to the increasing resistance of Candida towards antifungal compounds and the limited choice of therapeutic drugs, searching for new antifungal compound is necessary. $W$. anomalus and A. pullulans with mycocinogenic activity have been isolated from fermented food and the natural environment in our study recently $[8,9]$. Herein, we describe our investigation on the growth inhibition of Candida species by W. anomalus mycocin and a lactone compound from $A$. pullulans.

\section{Methods}

\section{Yeasts and assessment of mycocin activity}

W. anomalus strain tp2-15 and A. pullulans strain L7-10 isolated from fermented tapioca and a plant leaf, respectively, from two previous studies were used in this study $[8,9]$. Identification of yeast strains was performed by sequence analysis of the yeast internal transcribed spacer (ITS) regions. Analysis using BLAST (Basic Local Alignment Search Tool) at NCBI database revealed 100\% sequence similarities of the strain tp2-15 with $W$. anomalus strain MUCL 51259 from Belgium (585/585 nucleotides, Genbank accession no. FN394001) [23]. The strain tp2-15 differed in 1 nucleotide (gap) compared to the type strain of $W$. anomalus (AY046221). The strain L7-10 showed $100 \%$ sequence similarity with that of $A$. pullulans isolate BK6 from Thailand (574/574 nucleotides, Genbank accession no. AY225164) [24]. Queries at ISHAM ITS database (http://its.mycologylab.org/) show that the sequence of strain tp2-15 was $100 \%$ similarity with several $W$. anomalus reference sequences (MITS501, 502, 492, 490, 511, 520, 513-516) in the database, while the sequence of strain L710 was most identical (99.827\% similarity, 1 gap) with the reference sequence of a $A$. pullulans strain (MITS374). ITS sequence of the strain L7-10 showed 99\% similarity to the neotype strain of A. pullulans var. pullulans (FJ150906), 99\% similarity to the type strain of A. pullulans var. namibae (FJ150875), 99\% similarity to the type strain of A. pullulans var. melanogenum (FJ150886) and 98\% similarity to the type strain of A. pullulans var. subglaciale (FJ150895). The closest match among the type strains (6 substitutions) was observed with the neotype strain of $A$. pullulans var. pullulans and the neotype strain of $A$. pullulans var. namibae.

The sensitivity strains used for assessment of mycocinogenic activity in this study were C. albicans ATCC 90028, C. parapsilosis ATCC22019 and C. krusei ATCC6258. Additionally, due to the unavailability of reference strains, clinical cultures of $C$. dubliniensis (designated as strain 2879) [25] and a member of C. rugosa species complex (designated as 3209, Genbank accession no. HM641831) [26] were also used. According to the recent reassessment of the C. rugosa species complex, the strain 3209 has been reidentified as C. mesorugosa [13].

A well diffusion assay was used for assessment of the mycocin activity, as described previously $[8,9]$. Briefly, overnight cultures of sensitive strain were suspended in sterile distilled water to obtain about $10^{5}$ cells $/ \mathrm{ml}(80 \%$ transmittance at $530 \mathrm{~nm}$ followed by 10X dilution). The yeast suspension was spread using a sterile swab on a YEPD-MB agar plate. Yeasts were then point-inoculated in duplicate on the agar plate. The plate was incubated at $30^{\circ} \mathrm{C}$ for $72 \mathrm{~h}$ and inspected daily for the appearance of inhibition zone surrounding the inoculated area as an indication of mycocinogenic activity. 
As the inhibitory effect of $W$. anomalus was observed only against $C$. rugosa complex as demonstrated in the previous study [8], the same strain (3209) was used as a sensitive strain for subsequent study. For testing of antiCandida metabolite from $A$. pullulans, C. albicans reference strain SC5314 was used for assessment of $A$. pullulans metabolites in the study. Additionally, a total of 92 clinical isolates from various Candida species were used to investigate the inhibitory effects using broth microdilution and biofilm quantitation methods. The isolates included C. glabrata ( $\mathrm{n}=26)$, C. krusei $(\mathrm{n}=17)$, C. albicans ( $\mathrm{n}=15), C$. parapsilosis $(\mathrm{n}=8), C$. tropicalis $(\mathrm{n}=10), C$. orthopsilosis ( $\mathrm{n}=8)$, C. rugosa species complex ( $\mathrm{n}=5), C$. dubliniensis $(\mathrm{n}=1)$, Meyerozyma guilliermondii $(\mathrm{n}=1)$ and C. metapsilosis $(\mathrm{n}=1)$. These isolates had been identified using API 20C AUX system (bioMerieux, Marcy, l'Etoile, France) or sequence analysis of their ITS gene regions prior to susceptibility testing.

\section{Isolation and purification of $W$. anomalus mycocin}

Strain tp2-15 was cultivated in YEPD broth $(1000 \mathrm{ml})$ buffered with $50 \mathrm{mM}$ sodium phosphate citric acid $(\mathrm{pH} 4.5)$ at $30^{\circ} \mathrm{C}$ and $120 \mathrm{rpm}$ in a gyratory shaker (Stuart, UK) for 3 days. The culture supernatant was filtered through a $0.22 \mu \mathrm{m}$ filter system (Sartorius, Germany) and added with ice-cold ethanol (Fisher Scientific, USA) to a final concentration of $70 \%(\mathrm{v} / \mathrm{v})$. The mixture was then incubated at $-20^{\circ} \mathrm{C}$ for $1 \mathrm{~h}$ and centrifuged at 12,000 rpm at $4^{\circ} \mathrm{C}$ for $45 \mathrm{~min}$. The pellet was resuspended in $10 \mathrm{ml}$ of $50 \mathrm{mM}$ sodium phosphate citric acid buffer ( $\mathrm{pH} 4.5)$ incorporated with $20 \%$ glycerol and filtered. For determination of $\mathrm{pH}$ stability, mycocin samples were prepared in $50 \mathrm{mM}$ sodium phosphate citric acid buffered at different $\mathrm{pHs}$ (ranging from 3 to 6). The mycocin activity was assessed by a well diffusion assay as described above except that the samples were pipetted into wells of approximately $10 \mathrm{~mm}$ in diameter in the YEPD-MB agar plate. For thermal stability study, mycocin samples were buffered at $\mathrm{pH} 4.5$ and incubated at different temperatures: 4, $25,30,37,50,70$ and $100^{\circ} \mathrm{C}$ for $1 \mathrm{~h}$ before the mycocin activity was assessed.

For purification of the mycocin, Sephadex G-75 gel slurry (product code: 17-0050-01, lab packs, GE healthcare, USA) in $50 \mathrm{mM}$ sodium phosphate citric acid buffer ( $\mathrm{pH} 4.5)$ was packed into a column of $1.8 \mathrm{~cm}$ (diameter) $\times$ $100 \mathrm{~cm}$ (length) to $80 \mathrm{~cm}$ in length and equilibrated with the same buffer at a rate of $1 \mathrm{ml} / \mathrm{min}$. Seven milliliters of the above mycocin preparation were then loaded onto a Sephadex G-75 gel-filtration column. Elution was performed using the same buffer at a flow rate of $1 \mathrm{ml} / \mathrm{min}$ at $4^{\circ} \mathrm{C}$. Fractions of $2 \mathrm{ml}$ were collected and filtered through $0.2 \mu \mathrm{m}$ pore size filters (Sartorius, Germany) for mycocin testing. The presence of protein in the fractions was determined by measuring the UV absorbance (at $280 \mathrm{~nm}$ ) using a Nanophotometer ${ }^{\mathrm{TM}}$ (Implen GmbH, Germany). Fractions with mycocin activity were pooled and concentrated using a $10 \mathrm{kDa}$-cut off ultrafilter (Vivaspin 20, Sartorius, Germany). The mycocin activity was determined using a microplate assay as described by Hodgson et al. [16]. Briefly, $100 \mu \mathrm{l}$ mycocin preparation was mixed with equal volume of $C$. mesorugosa cell suspension pre-adjusted to $10^{5}$ cells/ml in RPMI 1640 medium (Sigma-Aldrich, USA) in a microtiter well and incubated at $30^{\circ} \mathrm{C}$ for $24 \mathrm{~h}$. Yeast growth was determined by measuring $\mathrm{OD}_{450}$ using a microplate reader (Glomax, Promega, USA). Mycocin activity was expressed as the percentage growth inhibition of the sensitive strain compared to a mycocin-free control (i.e. $50 \mathrm{mM}$ sodium phosphate citric acid buffer, $\mathrm{pH} 4.5$ ).

SDS-PAGE was performed according to Laemmli [27] using a concentrated sample from the active fractions in a mini-PROTEAN ${ }^{\circ}$ Tetra Cell electrophoresis system (Biorad, USA) A $4 \%(\mathrm{w} / \mathrm{v})$ acrylamide was used in the stacking gel and $10 \%(\mathrm{w} / \mathrm{v})$ acrylamide was used in the resolving gel. After electrophoresis, the protein was stained with Coomassie brilliant blue R-250 (SigmaAldrich, USA) and the molecular mass was determined by comparison with known marker proteins (Fermentas, Lithuania). The protein fragments in the SDS-PAGE gel was identified by MALDI TOF/TOF mass spectrometry (Proteomics International, Australia) using a 5800 Proteomics Analyzer (AB Sciex, USA).

Discontinuous Native PAGE was performed to detect glucanase activity from the active fractions as described by Nebrada et al. [28]. After electrophoresis, the native gel was incubated with $0.2 \%$ 4-methyl-umbelliferyl- $ß-D-g l u-$ coside (MUG) (Sigma-Aldrich: M-3633, USA) in $50 \mathrm{mM}$ acetate buffer ( $\mathrm{pH} \mathrm{5.0)}$ at $30^{\circ} \mathrm{C}$ for $45 \mathrm{~min}$. Protein with glucanase activity will be visualized as a fluorescence band on a UV transilluminator (Syngene, UK).

\section{Isolation and identification of a lactone compound from A. pullulans}

Strain L7-10 was cultured in a broth containing $0.67 \%(\mathrm{w} / \mathrm{v})$ yeast nitrogen base medium supplemented with $2 \%(\mathrm{w} / \mathrm{v})$ glucose at $30^{\circ} \mathrm{C}$ with agitation $(120 \mathrm{rpm})$ for seven days. The culture broth was then separated from the biomass by centrifugation at $4000 \mathrm{rpm}$ for $30 \mathrm{~min}$ and filtered through a $0.22 \mu \mathrm{m}$ filter membrane (Sartorius Stedim Biotech $\mathrm{GmbH}$, Germany). A total of 12 liters of culture filtrate was extracted three times with ethyl acetate before fractionating using a $40 \times 100 \mathrm{~mm}$ Prep Nova-Pak HR C18 column (Waters Co., Milford, MA, USA) in a Prep-HPLC system. Twelve fractions (A to $\mathrm{L}$ ) were collected and each fraction was adjusted to $1 \mathrm{mg} / \mathrm{ml}$ prior to testing using a biofilm quantitation method [9].

The identification of compound in the active fractions was performed using Shimadzu GC-17A gas chromatography, GCMS-QP5050A mass spectrometer and a capillary 

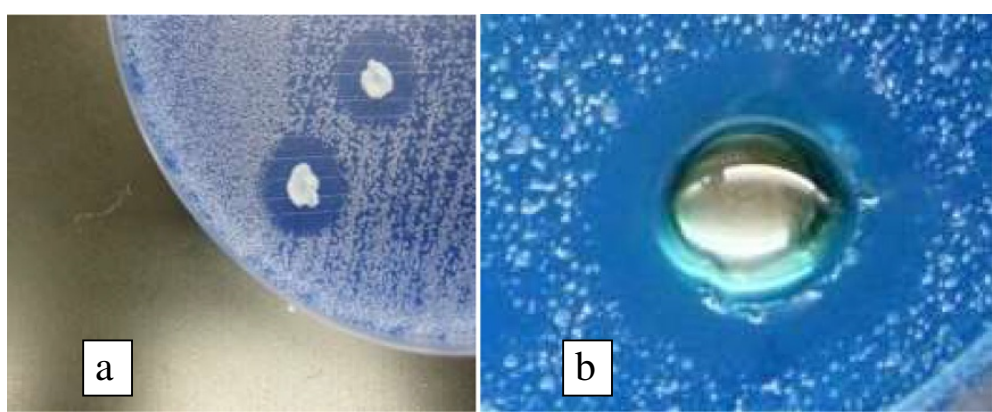

Figure 1 Killer activity by (a) cultures of $W$. anomalus killer yeast and (b) an ethanol-precipitated mycocin sample, against $C$. mesorugosa on a YEPD-MB agar plate.

column Zebron ZB-1 (30 m X 0.25 mm X $0.25 \mu \mathrm{m}$ diameter). GC-MS was performed using splitless injection with the following setting: injector at $250^{\circ} \mathrm{C}$, column at $50^{\circ} \mathrm{C}$, heating ramp of $5^{\circ} \mathrm{C} / \mathrm{min}$, final temperature of $300^{\circ} \mathrm{C}$, and MS/FID detector at $280^{\circ} \mathrm{C}$. Helium was used as a carrier gas at $1.4 \mathrm{ml} / \mathrm{min}$. The GC-MS electron ionization system was set at $70 \mathrm{eV}$. Identification of active compound was made by comparison with the database from WILEY 229 library of mass-spectra, National Institute of Standards and Technology (NIST) 107 and NIST 21.

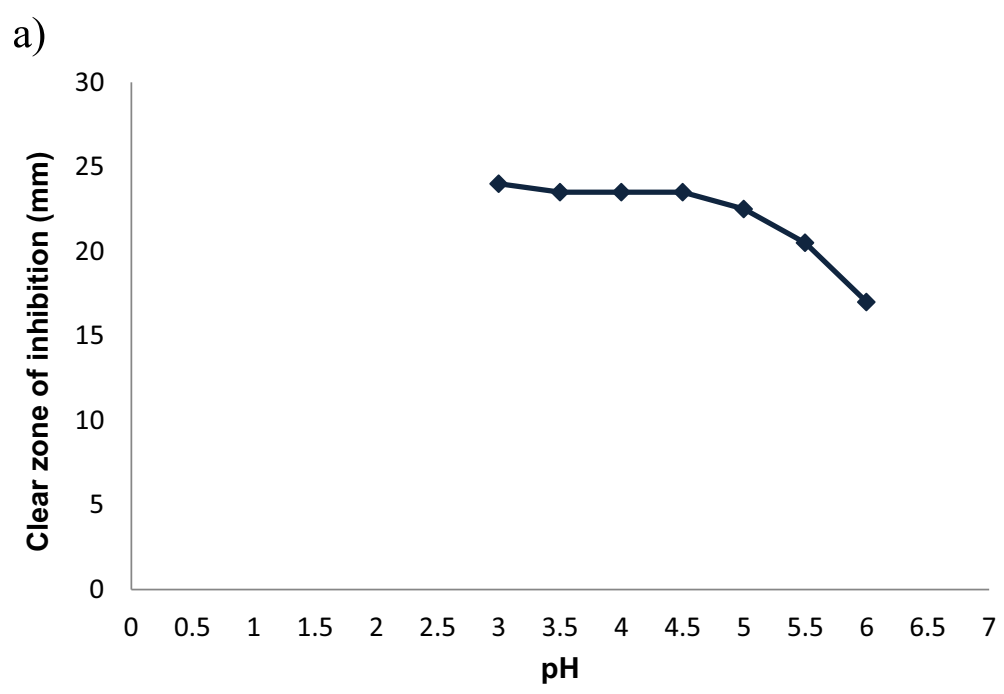

b)

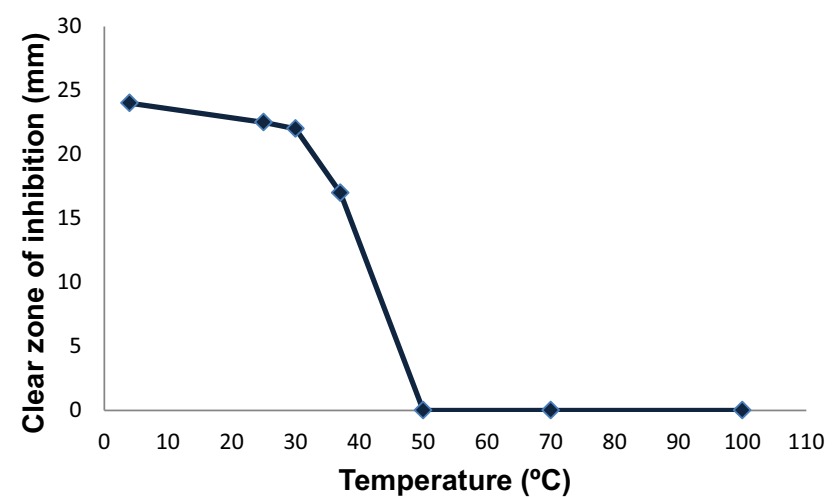

Figure 2 Determination of the effect of (a) $\mathrm{pH}$ and (b) temperature on the activity of $W$. anomalus mycocin. 
Due to the limited availability of the lactone compound for testing, 5-hydroxy-2-decenoic acid lactone (abbreviated as HDCL, CAS no: 54814-64-1) was obtained from Penta International Corp., Livingston, USA. A stock solution of HDCL was prepared at $450 \mathrm{mg} / \mathrm{ml}$ in DMSO (AMRESCO, Cleveland, Ohio, USA). For determination of the susceptibility of 92 isolates of various Candida species, final concentrations of HDCL ranging from 8 to $4096 \mu \mathrm{g} / \mathrm{ml}$ were prepared in RPMI 1640 broth medium with L-glutamine, without bicarbonate (Sigma Aldrich, USA), and buffered with MOPS medium ( $\mathrm{pH}$ 7.0). The MICs of the isolates were determined by broth microdilution method as in accordance to CLSI method (2008).

The biofilm MIC of the isolates was determined as described by Melo et al. [29]. Briefly, an overnight yeast culture was suspended in RPMI 1640 broth medium supplemented with L-glutamine and buffered with MOPS (Sigma, USA) and adjusted to $10^{7}$ cells $/ \mathrm{ml}$ $\left(\mathrm{OD}_{530 \mathrm{~nm}}=0.38\right)$ prior to use. One hundred microliters of the yeast suspension was then transferred to each well of a flat-bottomed, 96-well polystyrene microtiter plate. After incubation under shaking condition (75 rpm) at $37^{\circ} \mathrm{C}$ for $1.5 \mathrm{~h}$, unattached cells were removed by washing twice with $150 \mu$ l phosphate-buffered saline (PBS). Fresh RPMI 1640 medium $(100 \mu \mathrm{l})$ was then added to the microtiter well to allow proliferation of the biofilm for $24 \mathrm{~h}$. The biofilm cells were washed once with PBS before exposure to $100 \mu \mathrm{l}$ of HDCL solutions (final concentration ranging from 8 to $4096 \mu \mathrm{g} / \mathrm{ml}$ ). The metabolic activity of biofilms after 48 hours of exposure to HDCL was assessed using XTT reduction assays as described by Jin et al. [30]. Briefly, the biofilm in each well was washed twice with $200 \mu \mathrm{l}$ PBS before adding with a solution containing 2,3-bis(2-methoxy-4-nitro-5-sulfophenyl)-5-(phenylamino)carbonyl)-2Htetrazolium hydroxide (XTT) with menadione. The absorbance of the resultant solution $(100 \mu \mathrm{l})$ after incubation for $1 \mathrm{~h}$ in the dark was measured using a spectrophotometer at $492 \mathrm{~nm}$. The biofilm MIC of each Candida isolate was determined on the basis of a $50 \%$ reduction in metabolic activity compared with the metabolic activity of the

a)

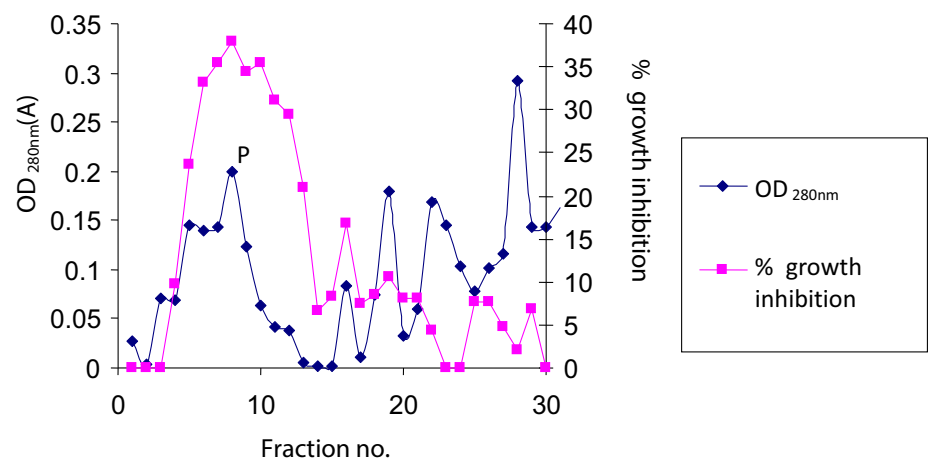

b)

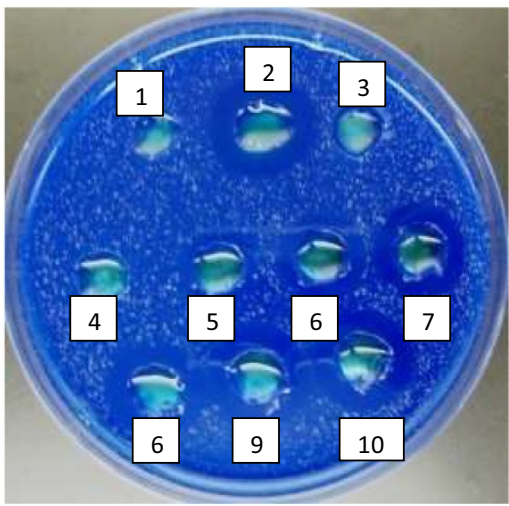

Figure 3 Determination of the mycocin activity of fractions eluted from Sephadex gel filtration column against $C$. mesorugosa by microplate assay (a): the highest growth inhibition against $C$. mesorugosa was shown in fraction 8 which corresponded with a protein peak (P); and well diffusion assay (b): 1, void sample; 2, ethanol-precipitated mycocin sample; 3 to 10,1 to 8 eluted fractions. 
biofilm without exposure to HDCL. The experiments were performed in duplicate.

\section{Results}

Isolation and identification of $W$. anomalus mycocin

Figure 1 shows the inhibitory effects of $W$. anomalus culture and the ethanol-precipitated mycocin preparation against C. mesorugosa (strain 3209) using well diffusion assay on a YEPD-MB agar plate. Clear zone of inhibition (about 2-3 $\mathrm{mm}$ from the edge to the colony/well) was observed for both $W$. anomalus culture and the ethanolprecipitated mycocin preparation after 2 days of incubation. Figure 2 shows that the mycocin was active at $\mathrm{pH} 3-6$ when incubated at $30^{\circ} \mathrm{C}$. The mycocin activity was detected when incubated at $4,25,30$ and $37^{\circ} \mathrm{C}$, but no activity was detected beyond $50^{\circ} \mathrm{C}$. A total of 30 fractions were eluted from the Sephadex G-75 gel column for determination of mycocin activity. Fraction 8 demonstrated the highest growth inhibition against the yeast by microplate assay (Figure 3a) and well diffusion assay (Figure 3b).

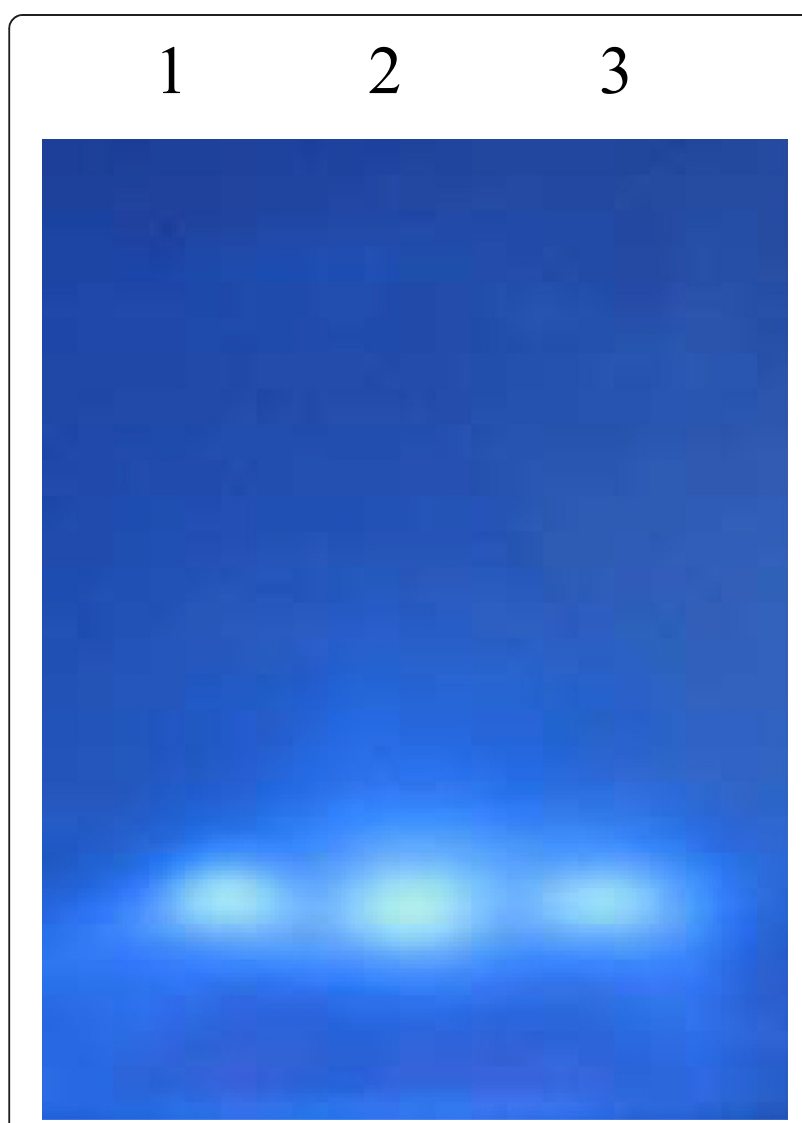

Figure $4 \mathrm{~A}$ fluorescent activity band was observed in the ethanol-precipitated culture supernatant of three batches of $W$. anomalus, indicating the presence of $B-1,3$-glucanase activity (Lane 1 to 3). ß-1,3-glucanase activity was detected by overlaying the native gel with $0.2 \%$ (wt/vol) MUG in acetate buffer $(\mathrm{pH}$ 5) and incubating for $45 \mathrm{~min}$ at $30^{\circ} \mathrm{C}$ before UV illumination.
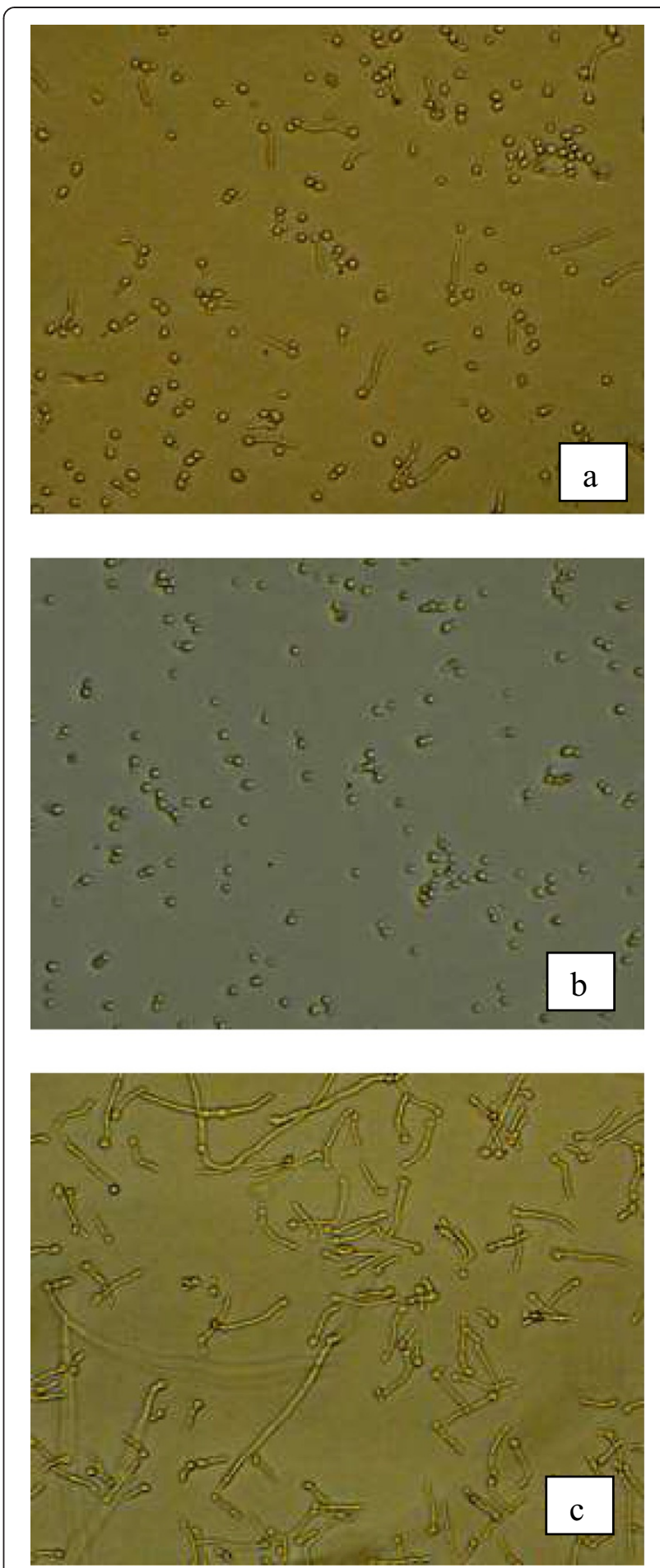

Figure 5 The effects of (a) fraction $\mathrm{J}(\mathrm{b})$ fraction $\mathrm{K}$ derived from culture supernatant of $A$. pullulans on the biofilm development of C. albicans reference strain SC5314 (yeast cells were co-incubated with crude extract and allowed to proliferate for $24 \mathrm{~h}$ ) (c) negative control (normal growth medium was used instead of crude extract). 
SDS-PAGE analysis of a concentrated active fraction revealed four major protein fragments (data not shown). Mass spectrometry analysis demonstrated the identification of two fragments (45 kDa and $50 \mathrm{kDa}$ ) as exo- $\beta$ 1,3-glucanase. Both fragments demonstrated the closest match to that of the glucanase derived from a marine yeast, $P$. anomala YF07b (A0MPR7) which inhibited the growth of Metschnikowia bicuspidata, a pathogenic yeast causing milky disease in crab [31]. A peptide sequence of GDYWDYQND KIR was detected from the fragment with the molecular weight of $45 \mathrm{kDa}$, while three matching peptides (GDYWDYQND KIR, LNDFWQQGYHNLR and WLNGVGR) were detected from the fragment with the molecular weight of $50 \mathrm{kDa}$. MUG staining of native gel with the mycocin samples showed the presence of fluorescent activity bands, indicating the association of glucanase activity with the W. anomalus mycocin (Figure 4).

\section{Isolation and purification of lactone compound from $A$. pullulans}

Only two fractions ( $J$ and $K$ ) exhibited inhibitory effect against biofilm cultures of $C$. albicans. Microscopic analysis showed inhibition of hyphal extension by fractions J and $\mathrm{K}$, whereas extensive hyphal filaments were observed for the negative control (untreated cells) after $72 \mathrm{~h}$ of incubation (Figure 5). GC-MS analysis revealed the presence of 5-hydroxy-2-decenoic acid lactone (95\% match, Figure 6) in the fraction K. The lactone compound is characterized by a closed ring containing two or more carbon atoms and a single oxygen atom, with a

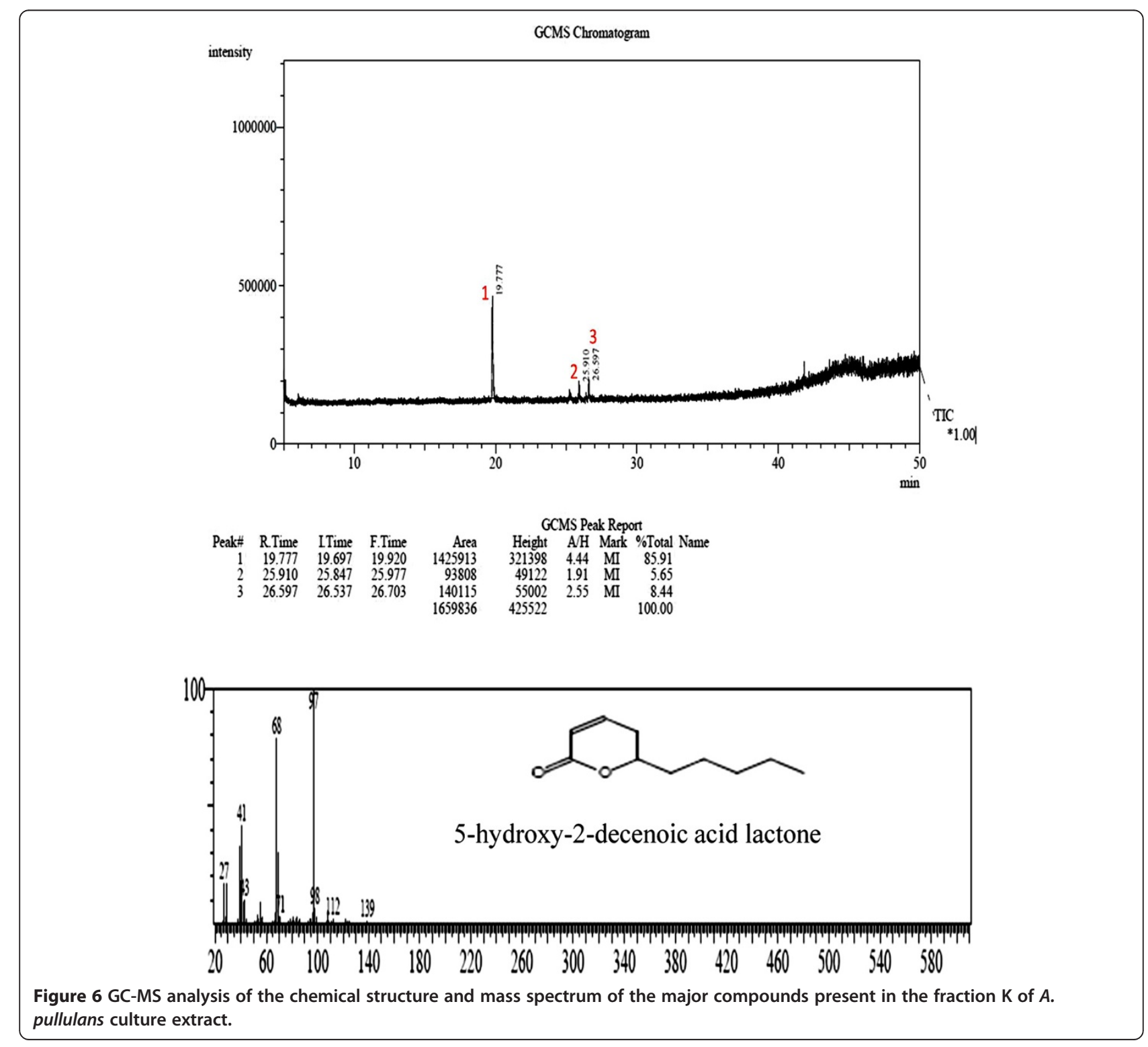


ketone group $(=\mathrm{O})$ in one of the carbons adjacent to the other oxygen.

Table 1 shows the susceptibility profiles of Candida isolates to the commercial source of 5-hydroxy-2-decenoic acid lactone (abbreviated as HDCL). The planktonic MICs range, $\mathrm{MIC}_{50}$ and $\mathrm{MIC}_{90}$ of HDCL against the isolates were 64 to $256 \mu \mathrm{g} / \mathrm{ml}, 256 \mu \mathrm{g} / \mathrm{ml}$ and $256 \mu \mathrm{g} / \mathrm{ml}$, respectively. Compared to other isolates, Candida parapsilosis isolates showed the lowest $\mathrm{MIC}_{50}$ values $(64 \mu \mathrm{g} / \mathrm{ml})$. The planktonic $\mathrm{MIC}_{50}$ and $\mathrm{MIC}_{90}$ of nonalbicans Candida species including Candida krusei, C. glabrata, C. parapsilosis, C. tropicalis, C. orthopsilosis and C. rugosa species complex were $256 \mu \mathrm{g} / \mathrm{ml}$. The biofilm $\mathrm{MIC}$ range, $\mathrm{MIC}_{50}$ and $\mathrm{MIC}_{90}$ of the Candida yeasts were 64 to $1024 \mu \mathrm{g} / \mathrm{ml}, 256 \mu \mathrm{g} / \mathrm{ml}$ and $512 \mu \mathrm{g} / \mathrm{ml}$, respectively (Table 1). Compared to other species, Candida krusei, C. parapsilosis and C. orthopsilosis isolates exhibited the lowest $\mathrm{MIC}_{50}$ values $(128 \mu \mathrm{g} / \mathrm{ml})$. The overall biofilm $\mathrm{MIC}_{50}$ and $\mathrm{MIC}_{90}$ of non-albicans Candida species were both $256 \mu \mathrm{g} / \mathrm{ml}$.

\section{Discussion}

Research in mycocinogenic yeasts has improved our understanding on the eukaryotic cell biology, host-virus interaction and the mechanisms of eukaryotic secretion pathway $[2,3,5,6]$. W. anomalus (previously known as $P$. anomala) producing anti-Candida toxins have been reported in several studies [32-34]. In this study, the protein isolated from $W$. anomalus exhibited basic characteristics of mycocin with pH 3-6 and temperature ranging from 4 to $37^{\circ} \mathrm{C}$. Additionally, the mycocin was identified as exo- ß-1,3 glucanase by mass spectrometry analysis and its activity was confirmed by MUG staining.

Glucanase is produced by yeasts to facilitate morphogenesis and recycling of cell wall components [35,36]. Table 2 summarizes the features of mycocins derived from four P. anomala strains (WC65, NCYC 432, 434, YF07b) which had been purified by various chromatographic methods [34,37,38]. All mycocins were active at low $\mathrm{pH}$. The mycocin for WC65 strain had the highest molecular weight $(83.3 \mathrm{kDa})$ compared to others $[37,38]$. The mycocin isolated from this study shared similar characteristics $(\mathrm{pH}$, temperature and molecular weight) as those reported for NCYC 432, 434, YF07b strains [37,38]. However, unlike other mycocins from $P$. anomala NCYC 434 and WC 65 which demonstrated inhibition against the growth of C. albicans, the mycocin investigated in this study was not inhibitory to $C$. albicans, instead, it was found to be only active against $C$. mesorugosa.

The different killer pattern of $W$. anomalus mycocin could be attributed to the specificity of glucanases which have selective preference for different types of glycosidic linkages and glucan receptors of the sensitive yeast strains [6,39-41]. Several investigators have proposed the use of mycocin for clarification of the taxonomy of closely related organisms [33,42]. Recently, C. rugosa has been differentiated to separate clade from other pathogenic Candida species including C. albicans, C. tropicalis, C. parapsilosis, based on multigene analyses [11]. Hence, the finding on the killer pattern of $W$. anomalus mycocin may reflect the different levels of taxonomic organization of this organism when compared to C. albicans.

Table 1 In vitro susceptibilities of Candida isolates to a standard preparation of HDCL

\begin{tabular}{|c|c|c|c|c|c|c|}
\hline \multirow[t]{2}{*}{ Candida spp. } & \multicolumn{3}{|c|}{ Planktonic MIC ( $\mu \mathrm{g} / \mathrm{ml})$} & \multicolumn{3}{|c|}{ Biofilm MIC ( $\mu \mathrm{g} / \mathrm{ml})$} \\
\hline & MIC range & $\mathrm{MIC}_{50}$ & $\mathrm{MIC}_{90}$ & MIC range & $\mathrm{MIC}_{50}$ & $\mathrm{MIC}_{90}$ \\
\hline Candida albicans $(n=15)$ & $128-256$ & 256 & 256 & $128-512$ & 256 & 256 \\
\hline Nonalbicans Candida species $(n=77)$ & $64-256$ & 256 & 256 & $64-1024$ & 256 & 256 \\
\hline Candida glabrata $(n=26)$ & $64-256$ & 256 & 256 & $64-512^{a}$ & $256^{a}$ & $512^{a}$ \\
\hline C. krusei $(n=17)$ & $128-256$ & 128 & 256 & $64-256$ & 128 & 256 \\
\hline C. parapsilosis $(n=8)$ & $64-256$ & 64 & 256 & $128-1024^{b}$ & $128^{b}$ & $1024^{b}$ \\
\hline C. tropicalis $(n=10)$ & $64-256$ & 128 & 256 & $256-1024$ & 256 & 512 \\
\hline C. orthopsilosis $(n=8)$ & $128-256$ & 256 & 256 & $128-256^{c}$ & $128^{c}$ & $256^{c}$ \\
\hline C. rugosa species complex $(n=5)$ & $128-256$ & 128 & 256 & $128-512$ & 512 & 512 \\
\hline C. dubliniensis $(n=1)$ & 128 & ND & ND & 256 & ND & ND \\
\hline M. guelliermondii $(n=1)$ & 128 & ND & ND & 128 & ND & ND \\
\hline C. metapsilosis $(\mathrm{n}=1)$ & 256 & ND & ND & 128 & ND & ND \\
\hline All isolates $(n=92)$ & $64-256$ & 256 & 256 & $64-1024$ & 256 & 512 \\
\hline
\end{tabular}

Footnote: Planktonic MIC: The lowest concentration of HDCL required to inhibit yeast growth after incubation at $37^{\circ} \mathrm{C}$ for $48 \mathrm{~h}$.

Biofilm MIC: The lowest concentration of $\mathrm{HDCL}$ required to cause $50 \%$ reduction in biofilm metabolic activity after incubation at $37^{\circ} \mathrm{C}$ for $48 \mathrm{~h}$.

$\mathrm{MIC}_{50}$ and $\mathrm{MIC}_{90}$ values were only calculated for those species with 5 or more isolates.

ND: Not determined.

a, b, c: Five Candida glabrata and two each of C. parapsilosis and C. orthopsilosis isolates were excluded from the study due to poor biofilm formation $\left(\mathrm{OD}_{490 \mathrm{~nm}}<0.1\right)$. 
Table 2 Source and features of $W$. anomalus mycocins

\begin{tabular}{|c|c|c|c|c|c|}
\hline $\begin{array}{l}\text { W. anomalus } \\
\text { strain }\end{array}$ & WC 65 [34] & NCYC 434 [37] & NCYC 432 [38] & YF07b [31] & $\begin{array}{l}\text { tp2-15 (isolated } \\
\text { in this study) }\end{array}$ \\
\hline Source & Culture collection & Culture collection & Culture collection & $\begin{array}{l}\text { Marine- } \\
\text { derived }\end{array}$ & Fermented tapioca \\
\hline pH stability & 2 to 5 & 3 to 5.5 & 3 to 5.5 & 3 to 5 & 3 to 6 \\
\hline $\begin{array}{l}\text { Temperature } \\
\text { stability }\left({ }^{\circ} \mathrm{C}\right)\end{array}$ & Not determined & Up to 37 & Up to 37 & $20-90$ & 4 to 37 \\
\hline $\begin{array}{l}\text { Molecular } \\
\text { weight (kDa) }\end{array}$ & 83.3 & 49 & 47 & 47 & 45,50 \\
\hline $\mathrm{pl}$ & 5.0 & 3.7 & $3.4 / 3.7$ & - & Not determined \\
\hline $\begin{array}{l}\text { Amino acid } \\
\text { sequence } \\
\text { analysis }\end{array}$ & Not determined & $\begin{array}{l}\text { Homology with exo-ß-1,3 } \\
\text { glucanase (accession no. } \\
\text { AJ222862) }\end{array}$ & $\begin{array}{l}\text { Homology with exo-ß- } \\
\text { 1,3 glucanase (accession } \\
\text { no. AJ222862) }\end{array}$ & $\begin{array}{l}\text { Exo-B-1,3 } \\
\text { glucanase } \\
\text { (AOMPR7) }\end{array}$ & $\begin{array}{l}\text { Homology } \\
\text { with exo-ß-1,3 } \\
\text { glucanase (AOMPR7) }\end{array}$ \\
\hline $\begin{array}{l}\text { Inhibitory } \\
\text { activity }\end{array}$ & $\begin{array}{l}\text { C. albicans, Cyberlindnera bimundalis, } \\
\text { Cyberlindnera jadinii, Kluyveromyces lactis, } \\
\text { Saccharomyces cerevisiae, } \\
\text { Saccharomycodes ludwigii }\end{array}$ & $\begin{array}{l}\text { C. albicans, Torulaspora } \\
\text { delbrueckii, Kluyveromyces } \\
\text { marxianus, Saccharomyces } \\
\text { cerevisiae }\end{array}$ & $\begin{array}{l}\text { C. albicans, C. tropicalis, } \\
\text { C. pseudotropicalis, C. } \\
\text { glabrata, C. parapsilosis, } \\
\text { C. krusei }\end{array}$ & $\begin{array}{l}\text { Metschnikowia } \\
\text { bicuspidata }\end{array}$ & C. mesorugosa \\
\hline
\end{tabular}

Mycocin has been proposed as a novel agent for treating fungal infections $[5,16-18,42]$. The fact that the target molecule for mycocin (glucan as for $W$. anomalus mycocin in this study) is absent in mammalian cells, suggests its potential application against fungal infections on the skin and mucosal membranes, as most mycocins are not suitable for oral or intravenous use, due to their sensitivity to proteinase degradation, antigenicity, and activity within a narrow $\mathrm{pH}$ range [42]. However, development of anti-idiotypic antibodies which share the active site of the mycocin and possess antifungal activity is possible $[5,18]$.

In this study, a lactone compound (5-hydroxy-2-decenoic acid lactone) inhibiting various Candida species was isolated from an ethyl-acetate extract of the culture supernatant of $A$. pullulans. Lactone is an analogue of 6-pentyl-2H-pyran-2-one (synonym: massoialactone), which has been reported as a byproduct of Trichoderma [43]. Some specific isolates of Aureobasidium also produced large amounts of delactonised massoialactone as an extracellular ester [44]. In vitro biological activity of massoialactone-related compounds against phytopathogens and human pathogens including $C$. albicans has been reported $[43,45]$. Several lactone compounds have been reported to be effective at preventing biofilm formation of bacteria or fungi. For instance, plant sesquiterpene lactones are inhibitory to the biofilm growth of $P$. aeruginosa [46] and 3-oxo- $\mathrm{C}_{12}$ homoserine lactone (3-oxo- $\mathrm{C}_{12}$-HSL) is inhibitory to $C$. albicans filamentation by blocking the yeast-to-hyphal switch [47]. Unlike amphotericin, azoles and caspofungin which target at the fungal cell wall, the antimicrobial mechanism responsible for massoialactone activity against $C$. albicans is probably through the inhibition of the fungal respiratory system [44]. However, data is limited as there has been no detail study on the use of the lactone compound against Candida yeasts.

HDCL demonstrated a broad spectrum of inhibitory action against multiple Candida species in this study. However, a high concentration of HDCL (at least $64 \mu \mathrm{g} / \mathrm{ml}$ ) was required to inhibit both planktonic and biofilm cultures of Candida yeasts. In our previous study, the amphotericin and fluconazole $\mathrm{MIC}_{50}$ against a culture collection of Malaysian clinical isolates of $C$. albicans and non-albicans Candida species were 0.25 and $2 \mu \mathrm{g} / \mathrm{ml}$, respectively [48]. An increased resistance of Candida biofilm cultures to amphotericin (more than 32 folds) and fluconazole $(\geq 128 \mu \mathrm{g} / \mathrm{ml})$ as compared to their planktonic counterparts was also reported in that study. In this study, there was no obvious difference in the HDCL MICs of both planktonic and biofilm cultures of Candida yeasts (Table 1).

\section{Conclusion}

The growth inhibition of $W$. anomalus mycocin and 5hydroxy-2-decenoic acid lactone from $A$. pullulans against Candida yeasts should be further explored for biotechnological applications and therapeutic potentials. Pathogenic fungi such as Aspergillus and dermatophytes may be included for future testing to broaden the spectrum of mycocin and the lactone compound. As little is known about yeast killing phenomena and mechanisms of actions, proteome profiling and gene expression studies of Candida in response to these molecules will be required.

\section{Competing interests}

The authors declare that they have no competing interests.

\section{Authors' contributions}

TST, LSL, THW took part in experimental design, acquisition of data, interpretation and writing of the manuscript. All authors read and approved the final version of manuscript. 


\section{Acknowledgements}

This study was funded by research grants provided by University of Malaya (No.: RG090-09HTM, RG378/11HTM and FP035-2014A). We would like to acknowledge the help given by Professor Tan NH from Department of Molecular Medicine, Prof. Debra Sim and Ms. Mala from Department of Pharmacology, and Puan Putri Narrima Mohd Fauzi from the SUCXES Laboratory, Department of Pharmacology, Faculty of Medicine, University of Malaya. The authors would like to thank Dr. Andrey Yurkov for his critical review of the manuscript, particularly on the taxonomy aspect of the yeasts investigated in this study.

Received: 30 December 2013 Accepted: 14 October 2014

Published: 8 November 2014

\section{References}

1. Golubev WI: Mycocins. In The Yeasts, A Taxonomic Study. 4th edition. Edited by Kurtzman CP, Fell JW. Amsterdan: Elsevier Science B.V; 1998:55-62.

2. Schmitt MJ, Breinig F: The viral killer system in yeast: from molecular biology to application. FEMS Microbiol Rev 2002, 26:257-276.

3. Bevan EA, Makower M: The physiological basis of the killer character in yeast. Proc Int Congr Genet 1963, 1:202-203.

4. Coda R, Cassone A, Rizzello CG, Nionelli L, Cardinali G, Gobbetti M: Antifungal activity of Wickerhamomyces anomalus and Lactobacillus plantarum during sourdough fermentation: identification of novel compounds and long-term effect during storage of wheat bread. Appl Environ Microbiol 2011, 77:3484-3492.

5. Magliani W, Conti S, Gerloni M, Bertolotti D, Polonelli L: Yeast killer systems. Clin Microbiol Rev 1997, 10:369-400.

6. Marquina D, Santos A, Peinado JM: Biology of killer yeasts. Int Microbiol 2002, 5:65-71

7. Walker GM: Pichia anomala: cell physiology and biotechnology relative to other yeasts. Antonie Van Leeuwenhoek 2011, 99:25-34.

8. Lim SL, Tay ST: Diversity and killer activity of yeasts in Malaysian fermented food samples. Trop Biomed 2011, 28:438-443.

9. Tan HW, Tay ST: Anti-Candida activity and biofilm inhibitory effects of secreted products of tropical environmental yeasts. Trop Biomed 2011, 28:175-180.

10. Chi Z, Wang F, Chi Z, Yue L, Liu G, Zhang T: Bioproducts from Aureobasidium pullulans, a biotechnologically important yeast. Appl Microbiol Biotechnol 2009, 82:793-804.

11. Tsui CK, Daniel HM, Robert V, Meyer W: Re-examining the phylogeny of clinically relevant Candida species and allied genera based on multigene analyses. FEMS Yeast Res 2008, 8:651-659.

12. Pfaller MA, Diekema DJ: Epidemiology of invasive candidiasis: a persistent public health problem. Clin Microbiol Rev 2007, 20:133-163.

13. Padovan AC, Melo AS, Colombo AL: Systematic review and new insights into the molecular characterization of the Candida rugosa species complex. Fungal Genet Biol 2013, 61:33-41.

14. Baillie GS, Douglas LJ: Effect of growth rate on resistance of Candida albicans biofilms to antifungal agents. Antimicrob Agents Chemother 1998, 42:1900-1905.

15. Seneviratne CJ, Jin LJ, Samaranayake YH, Samaranayake LP: Cell density and cell aging as factors modulating antifungal resistance of Candida albicans biofilms. Antimicrob Agents Chemother 2008, 52:3259-3266.

16. Hodgson VJ, Button D, Walker GM: Anti-Candida activity of a novel killer toxin from the yeast Williopsis mrakii. Microbiology 1995, 141:2003-2012.

17. Izgü F, Altinbay D, Türeli AE: In vitro susceptibilities of Candida spp. to panomycocin, a novel exo-beta-1,3-glucanase isolated from Pichia anomala NCYC 434. Microbiol Immunol 2007, 51:797-803.

18. Polonelli L, De Bernardis F, Conti S, Boccanera M, Gerloni M, Morace G, Magliani W, Chezzi C, Cassone A: Idiotypic intravaginal vaccination to protect against candidal vaginitis by secretory, yeast killer toxin-like anti-idiotypic antibodies. J Immunol 1994, 152:3175-3182.

19. Jeniel E, Nett JE, Ringeisen A, Holoyda KA, Andes DR: Reduced biocide susceptibility in Candida albicans biofilms. Antimicrob Agents Chemother 2008, 52:3411-3413.

20. Muthusamy K, Gopalakrishnan S, Ravi TK, Sivachidambaram P: Biosurfactants: properties, commercial production and application. Curr Sci 2008, 94:736-747.
21. Henriques M, Martins $M$, Azeredo J, Oliveira R: Effect of farnesol on Candida dubliniensis morphogenesis. Lett Appl Microbiol 2007 44:199-205.

22. Hornby JM, Jensen EC, Lisec AD, Tasto JJ, Jahnke B, Shoemaker R, Dussault $P$, Nickerson KW: Quorum sensing in the dimorphic fungus Candida albicans is mediated by farnesol. Appl Env Microbiol 2001, 67:2982-2992.

23. Vrancken $G$, De Vuyst $L$, Van der Meulen R, Huys G, Vandamme $P$, Daniel HM: Yeast species composition differs between artisan bakery and spontaneous laboratory sourdoughs. FEMS Yeast Res 2010, 10:471-481

24. Prasongsuk S, Sullivan RF, Kuhirun M, Eveleigh DE, Punnapayak H: Thailand habitats as sources of pullulan-producing strains of Aureobasidium pullulans. World J Microbiol Biotechnol 2005, 21:393-398.

25. Tay ST, Chai HC, Na SL, Ng KP: Molecular subtyping of clinical isolates of Candida albicans and identification of Candida dubliniensis in Malaysia. Mycopathologia 2005, 159:325-329.

26. Tay ST, Tan HW, Na SL, Lim SL: Phenotypic and genotypic characterization of two closely related subgroups of Candida rugosa in clinical specimens. J Med Microbiol 2011, 60:1591-1597.

27. Laemmli UK: Cleavage of structural proteins during the assembly of the head of bacteriophage T4. Nature 1970, 227:680-685.

28. Nebrada AR, Villa TG, Villanueva JR, Del Rey F: Cloning of genes related to exo-ß-1,3-glucanase production in Saccharomyces cerevisiae: characterization of an exo-ß-1,3-glucanase structural gene. Gene 1986, 47:245-249.

29. Melo AS, Colombo AL, Arthington-Skaggs BA: Paradoxical growth effect of caspofungin observed on biofilms and planktonic cells of five different Candida species. Antimicrob Agents Chemother 2007, 51:3081-3088

30. Jin Y, Yip HK, Samaranayake YH, Yau JY, Samaranayake LP: Biofilmforming ability of Candida albicans is unlikely to contribute to high levels of oral yeast carriage in cases of human immunodeficiency virus infection. J Clin Microbiol 2003, 41:2961-2967.

31. Wang $X, C h i Z$, Yue L, Li J: Purification and characterization of mycocin from a marine yeast Pichia anomala YF07b against the pathogenic yeast in crab. Curr Microbiol 2007, 55:396-401.

32. Mathews HL, Conti S, Witek-Janusek L, Polonelli L: Effect of Pichia anomala killer toxin on Candida albicans. Med Mycol 1998, 36:199-204.

33. Buzzini P, Martini A: Large-scale screening of selected Candida maltosa, Debaryomyces hansenii and Pichia anomala killer toxin activity against pathogenic yeasts. Med Mycol 2001, 39:479-482.

34. Sawant AD, Abdelal AT, Ahearn DG: Purification and characterization of the anti-Candida toxin of Pichia anomala WC 65. Antimicrob Agents Chemother 1989, 33:48-52.

35. Comitini F, Mannazzu I, Ciani M: Tetrapisispora phaffii mycocin is a highly specific $\beta$-glucanase that disrupts the integrity of the yeast cell wall. Microb Cell Fact 2009, 8:55.

36. Galan B, Garcia-Mendoza C, Colonje M, Novices-Ledieu M: Production, purification, and properties of an endo-1, 3- $\beta$-glucanase from the basidiomycete Agaricus bisporus. Curr Microbiol 1999, 38:190-193.

37. Izgu F, Altinbay D: Isolation and characterization of the K5-type yeast killer protein and its homology with an exo-beta-1,3-glucanase. Biosci Biotechnol Biochem 2004, 68:685-693.

38. İgü F, Altınbay D, Acun T: Killer toxin of Pichia anomala NCYC 432; purification, characterization and its exo- $\beta-1,3$-glucanase activity. Enzyme MicrobTechnol 2006, 39:669-676.

39. Peng Y, Chi Z, Wang X, Li J: Beta-1,3-glucanase inhibits activity of the killer toxin produced by the marine-derived yeast Williopsis saturnus WC91-2. Mar Biotechnol (NY) 2010, 12:479-485.

40. Gopal P, Sullivan PA, Shepherd MG: Isolation and structure of glucan from regenerating spheroplasts of Candida albicans. J Gen Microbiol 1984, 130:1217-1225.

41. Izgü F, Altinbay D, Sertkaya A: Enzymic activity of the K5-type yeast killer toxin and its characterization. Biosci Biotechnol Biochem 2005, 69:2200-2206

42. Golubev WI: The Yeast Handbook. "Biodiversity and Ecophysiology of Yeasts". Berlin: Springer-Verlag; 2006:197-219.

43. Cutler HG, Cox RH, Crumley FG, Cole PD: 6-Pentyl-pyrone from Trichoderma harzianum: its plants growth inhibitory and antimicrobial properties. Agr Biol Chem 1986, 50:2943-2945. 
44. Kishimoto N, Sugihara S, Mochida K, Fujita T: In vitro antifungal and antiviral activities of $\delta$ - and $\delta$-lactone analogs utilized as food flavoring. Biocontrol Sci 2005, 10:31-36.

45. Kurosawa T, Sakai K, Nakahara T, Oshima Y, Tabuchi T: Extracellular accumulation of the polyol lipids, 3,5-dihydroxydecanoyl and 5-hydroxy2-decenoyl esters of arabitol and mannitol, by Aureobasidium sp. Biosci Biotech Biochem 1994, 58:2057-2060.

46. Cartagena E, Colom OA, Neske A, Valdez JC, Bardón: Effects of plant lactones on the production of biofilm of Pseudomonas aeruginosa. Chem Pharm Bull (Tokyo) 2007, 55:22-25.

47. Hall RA, Turner KJ, Chaloupka J, Cottier F, De Sordi L, Sanglard D, Levin LR, Buck J, Mühlschlegel FA: The quorum-sensing molecules farnesol/homoserine lactone and dodecanol operate via distinct modes of action in Candida albicans. Eukaryot Cell 2011, 10:1034-1042.

48. Tay ST, Abidin IA, Hassan H, Ng KP: Proteinase, phospholipase, biofilm forming abilities and antifungal susceptibilities of Malaysian Candida isolates from blood cultures. Med Mycol 2011, 49:556-560.

doi:10.1186/1472-6882-14-439

Cite this article as: Tay et al: Growth inhibition of Candida species by Wickerhamomyces anomalus mycocin and a lactone compound of Aureobasidium pullulans. BMC Complementary and Alternative Medicine 2014 14:439

\section{Submit your next manuscript to BioMed Central and take full advantage of:}

- Convenient online submission

- Thorough peer review

- No space constraints or color figure charges

- Immediate publication on acceptance

- Inclusion in PubMed, CAS, Scopus and Google Scholar

- Research which is freely available for redistribution 